\title{
A report of short term spontaneous regression of herniated lumbar disc.
}

\section{AJAYA KUMAR AYYAPPAN UNNITHAN ( $\nabla$ drajayakumara@gmail.com )}

Mar Gregorios Memorial Muthoot Medical Centre https://orcid.org/0000-0003-1426-6662

\section{Research Article}

Keywords: Intervertebral Disc Displacement, Magnetic Resonance Inaging, Spontaneous Remission

Posted Date: June 7th, 2022

DOl: https://doi.org/10.21203/rs.3.rs-1334687/v2

License: (c) (i) This work is licensed under a Creative Commons Attribution 4.0 International License. Read Full License 


\section{Abstract}

Background and importance:

Spontaneous regression of herniated lumbar discs over a course of time is well documented in literature. But the concomitant relief of symptoms is not seen always. The reports of regression within 3 months are a few. Kim ES et al reported about the peroperative identification of regression of an extruded disc fragment, during microdiscectomy 2 months after the magnetic resonance imgaging(MRI).

Clinical presentation:

A 58-year lady presented with backache, left leg pain, and weakness for 3 months. A magnetic resonance imaging (MRI) scan of lumbosacral spine, taken three months back, showed L3-4 disc extrusion and canal stenosis and grade 1 listhesis at L5-S1. She had improvement with conservative treatment. But she had recurrence of symptoms 10 days back. Straight leg raising test was positive at 40 degree on left side. Dorsiflexion was grade 4 on left side. Sensations of touch and vibration were reduced in L4 dermatomal region.

A repeat MRI scan was done to plan surgery. The disc extrusion at L3-4 had shrunk, with the residual listhesis at L5-S1. She was given gabapentin, methylcobolamine, and physiotherapy. She improved over 1 week.

Conclusion:

Spontaneous regression of herniated lumbar disc can occur within three months, without corresponding symptomatic relief. So it is better to do a repeat imaging before planning surgery for a patient with a prior diagnosis of disc herniation. Thus an unnecessary surgery can be avoided.

\section{Background And Importance}

A large number of the extruded lumbar disc herniations have been found to regress over time. Kesikburun et al. have reported that about three-fourths of the patients with extruded lumbar disc herniation can have complete resolution in the repeat Magnetic resonance imaging(MRI) after an average follow-up period of 17 months $^{1}$. Turk et al. found that the average time for disappearance of extruded discs in MRI was 26 weeks ${ }^{2}$. But they noted that the patients continued to be symptomatic and even with deficits in spite of radiological improvement. Spontaneous regression was more common in sequestrated fragments than subligamentous disc herniations. Chiu et al. found that the rate of complete resolution of disc herniation was $43 \%$ for sequestrated discs and $15 \%$ for extruded discs ${ }^{3}$. The mechanisms behind the regression are dehydration, shrinkage, retraction, and resorption by inflammation ${ }^{4}$. Phagocytosis by macrophages has been observed. 
But the reports of spontaneous regression within a short term are few.Kim SG et al. described two male patients with clinical and radiological regression of lumbar discs in 3 months ${ }^{5}$. Albayraket al. published a report of regression of L5-S1 discsequestration of a 32-year-old man in 14 days $^{6}$. Kim ES et al. reported about a 58-year-old woman with a large L2-3 disc extrusion 7 . She underwent microdiscectomy after 2 months. But the expected disc fragment was not found. Immediate MRI showed the absence of the fragment.

\section{Clinical Presentation}

A 58-year lady presented with backache for 3 months, radiating to left leg, and weakness of left foot. She had severe pain 3 months back. A magnetic resonance imaging (MRI) scan of lumbosacral spine was taken at that time. It showed L3-4 disc extrusion and canal stenosis and grade 1 listhesis at L5-S1(Fig. 14). Surgery was advised at that time. But the patient opted conservative treatment. She had significant improvement in symptoms.

But she had recurrence of symptoms 10 days back. Straight leg raising test was positive at 40 degree on left side. Dorsiflexion was grade 4 on left side. Sensations of touch and vibration were reduced in L4 dermatomal region.

A repeat MRI scan was done to plan surgery.The disc extrusion at L3-4 had shrunk, with the residual listhesis at L5-S1(Fig. 5-7). She was given another trial of conservative treatment with gabapentin, methylcobolamine, and physiotherapy. She improved over 1 week in pain, power, and sensation.

\section{Discussion}

Spontaneous regression of herniated lumbar discs over a course of time is well documented in literature. But the concomitant relief of symptoms is not seen always. The reports of regression within 3 months are a few. Kim ES et al reported about the peroperative identification of regression of an extruded disc fragment. But in this case, it was detected prior to surgery with a repeat MRI. So an unwanted surgery was avoided. The probable mechanism of shrinkage may be either dehydration or resorption by inflammation, since the axial T2-weighted image shows a hypointense wrinkled fragment (Fig. 7). The knowledge of shrinkage of the extrusion helped in improvement of her symptoms, since psychological factors seem to play a major role in the outcome of low back pain as in the literature ${ }^{8}$.

\section{Conclusion}

Spontaneous regression of herniated lumbar disc can occur within three months, without corresponding symptomatic relief. So it is better to do a repeat imaging before planning surgery for a patient with a prior diagnosis of disc herniation. Thus an unnecessary surgery can be avoided.

\section{Declarations}


i. Funding - no external funding.

ii. Conflicts of interest/Competing interests - nothing to be disclosed.

iii. Ethics approval - obtained for retrospective analysis.

iv. Consent to participate - not applicable.

v. Consent for publication - written informed consent was obtained for publication of details in anonymised manner.

vi. Availability of data and material - nil.

vii. Code availability - not applicable.

viii. Authors' contributions- Treated the patient and prepared the manuscript.

\section{References}

1. Kesikburun B, Eksioglu E, Turan A, Adiguzel E, Kesikburun S, Cakci A. Spontaneous regression of extruded lumbar disc herniation: Correlation with clinical outcome. Pak J Med Sci. 2019;35(4):97480. doi:10.12669/pjms.35.4.346.

2. Turk O, Antar V, Yaldiz C. Spontaneous regression of herniated nucleus pulposus: The clinical findings of 76 patients. Med (Baltim). 2019;98(8):e14667. doi:10.1097/MD.0000000000014667.

3. Chiu CC, Chuang TY, Chang KH, Wu CH, Lin PW, Hsu WY. (2015) The probability of spontaneous regression of lumbar herniated disc: a systematic review. ClinRehabil,29(2):184-195. doi:10.1177/0269215514540919.

4. Cunha C, Silva AJ, Pereira P, Vaz R, Gonçalves RM, Barbosa MA. The inflammatory response in the regression of lumbar disc herniation. Arthritis Res Ther. 2018;20(1):251. doi:10.1186/s13075-0181743-4. Published 2018 Nov 6.

5. Kim SG, Yang JC, Kim TW, Park KH. Spontaneous regression of extruded lumbar disc herniation: three cases report. Korean J Spine. 2013;10(2):78-81. doi:10.14245/kjs.2013.10.2.78.

6. Albayrak S, Durdağ E, Atçı İB, Ayden Ö. Rapid Spontaneus Regression of Lumbar Disc Herniation Accompanying Neurological Recovery: Case Report. J Phys Med Rehabilitation Sciences/FizikselTupveRehabilitasyonBilimleriDergisi. 2012;15(3):89-91.

7. Kim ES, Oladunjoye AO, Li JA, Kim KD. Spontaneous regression of herniated lumbar discs. J ClinNeurosci. 2014;21(6):909-13. doi:10.1016/j.jocn.2013.10.008.

8. Pincus T, McCracken LM. (2013) Psychological factors and treatment opportunities in low back pain. Best Pract Res ClinRheumatol;27(5):625 - 35. doi: 10.1016/j.berh.2013.09.010. Epub 2013 Oct 5. PMID: 24315144. 
Figures

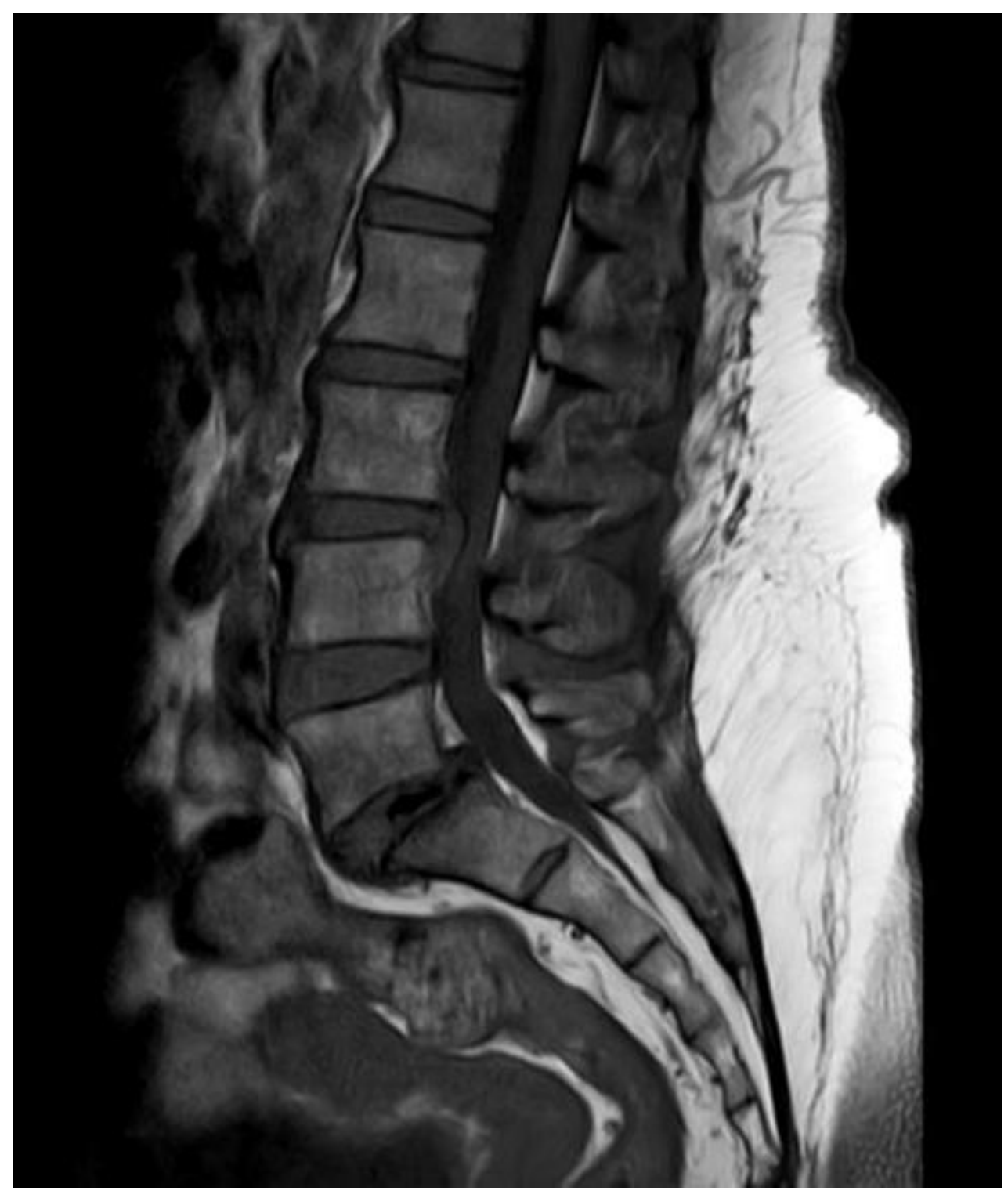

Figure 1

Sagittal T1-weighted MRI showing extrusion of L3-4 disc and grade 1 listhesis at L5-S1. 


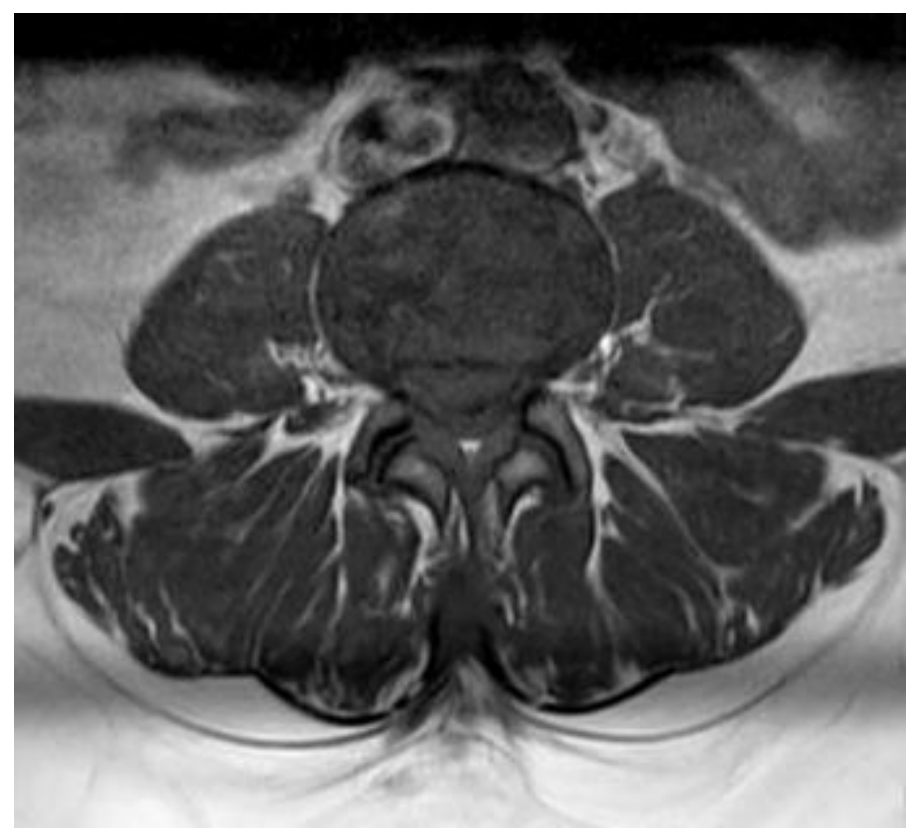

Figure 2

Axial T1-weighted imaging showing extrusion of L3-4 disc. 


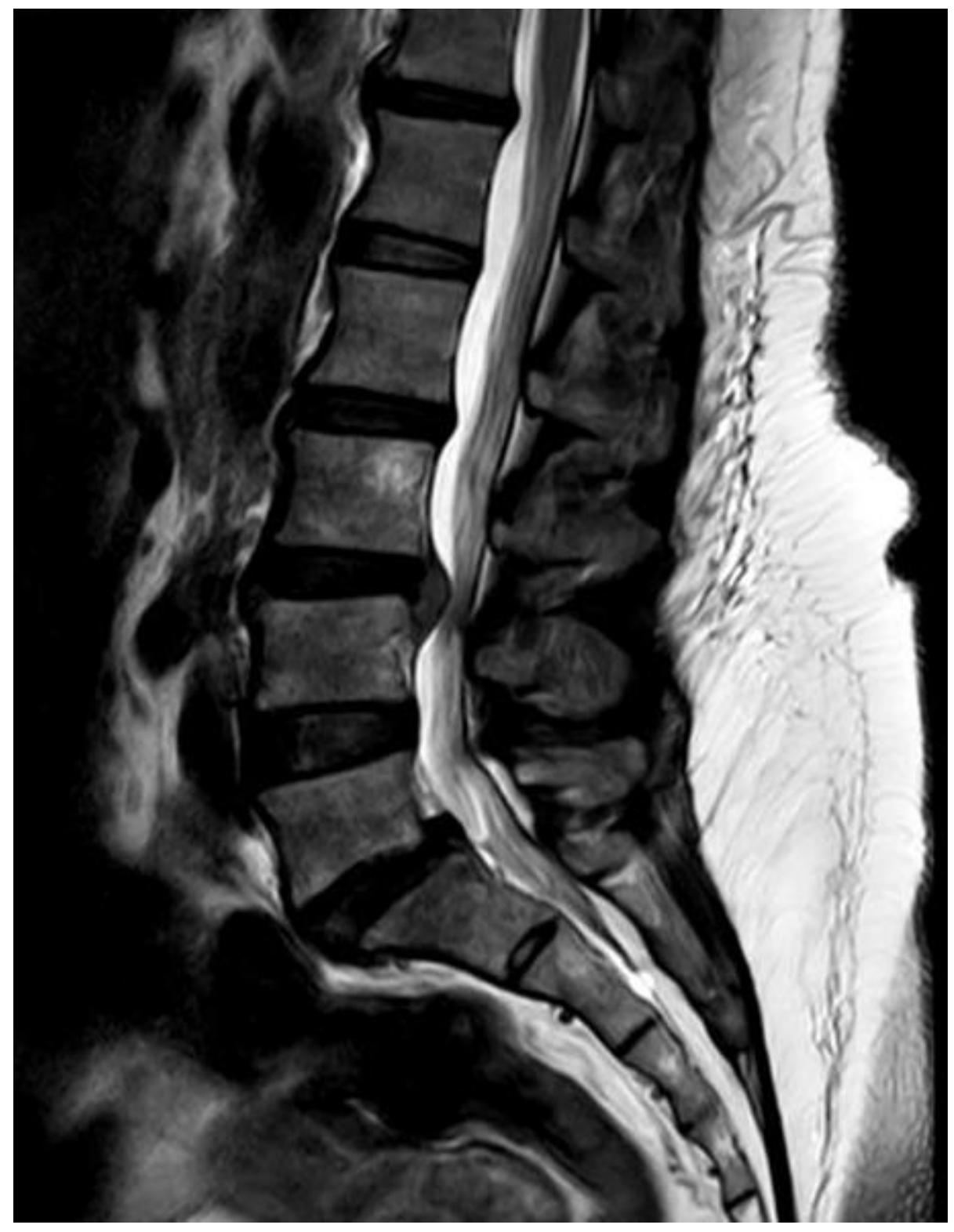

Figure 3

Sagittal T2-weighted MRI showing extrusion of L3-4 disc and grade 1 listhesis at L5-S1. 


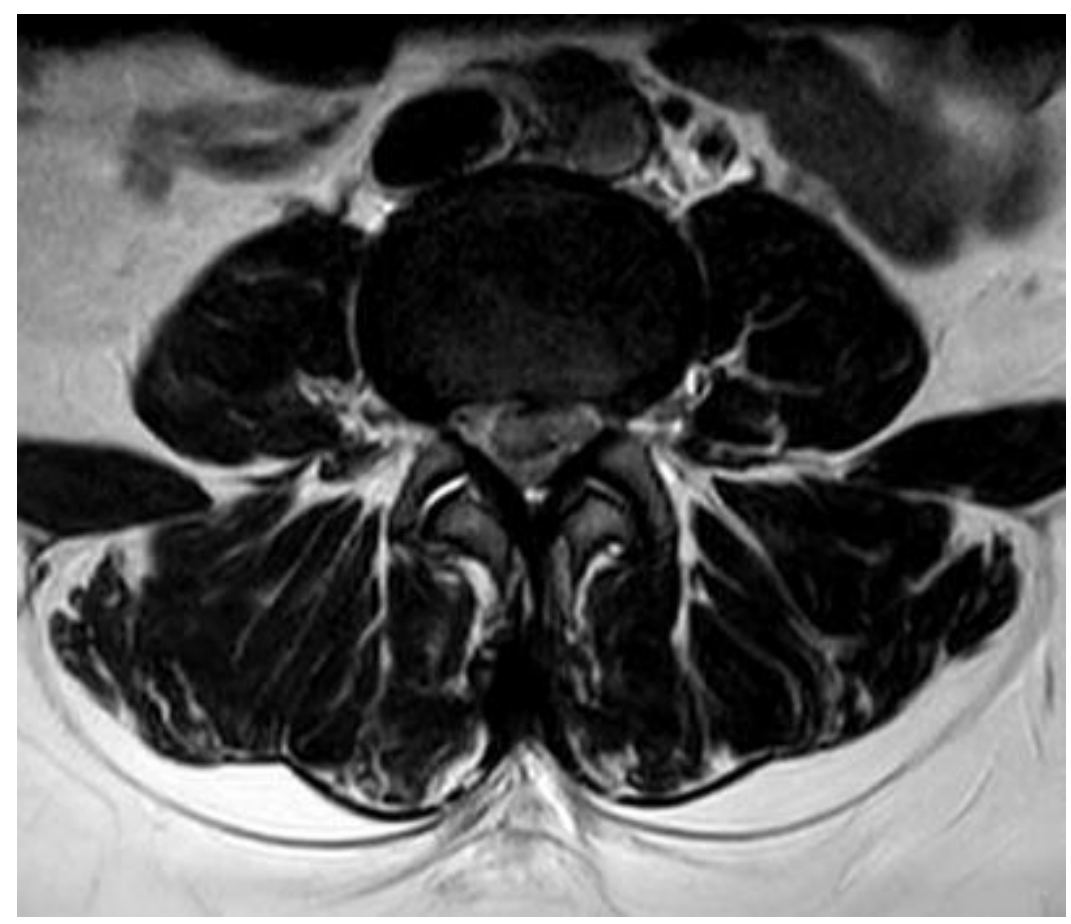

Figure 4

Axial T2-weighted imaging showing extrusion of L3-4 disc and canal stenosis.

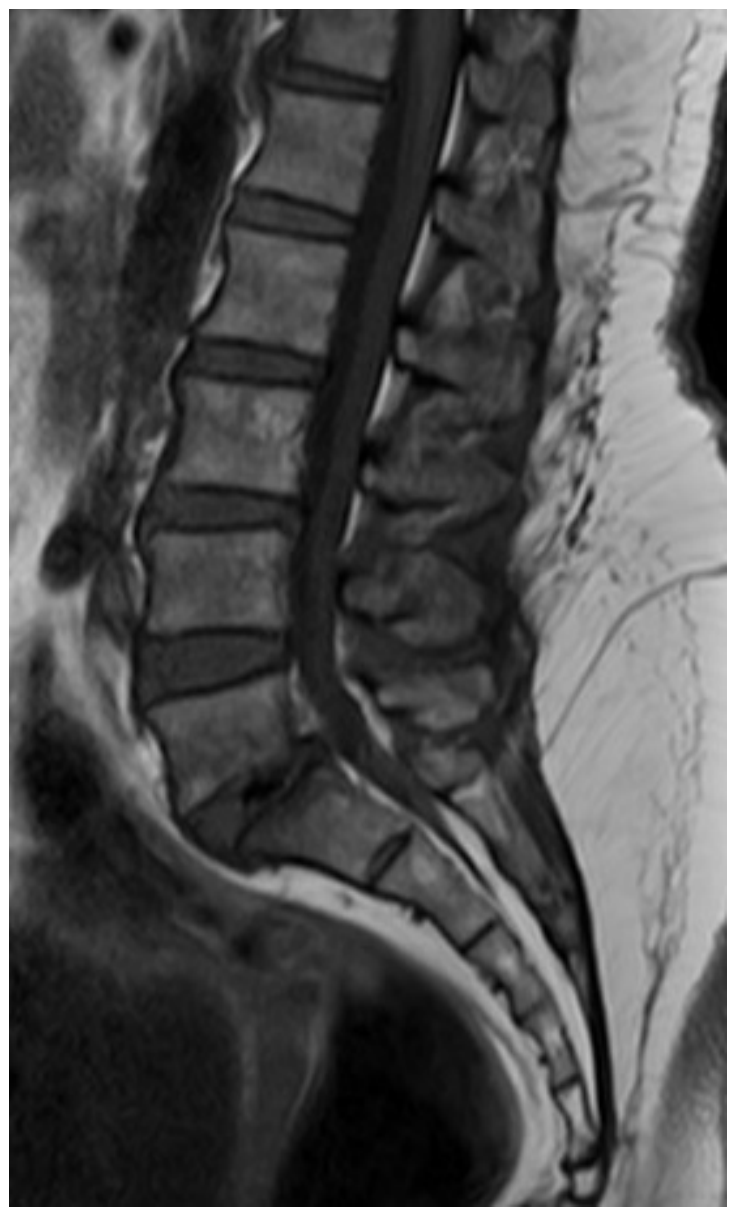

Figure 5 
Sagittal T1-weighted MRI showing regresseion of L3-4 disc extrusion.

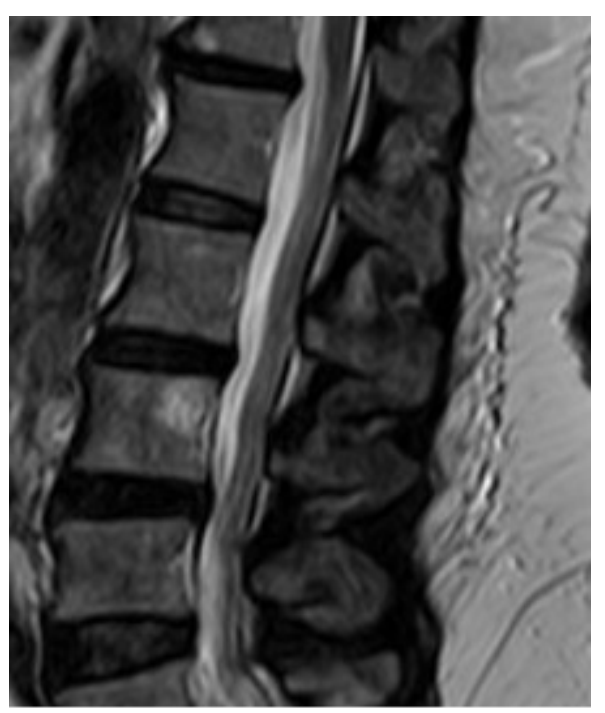

Figure 6

Sagittal T2-weighted MRI showing regresseion of L3-4 disc extrusion. 


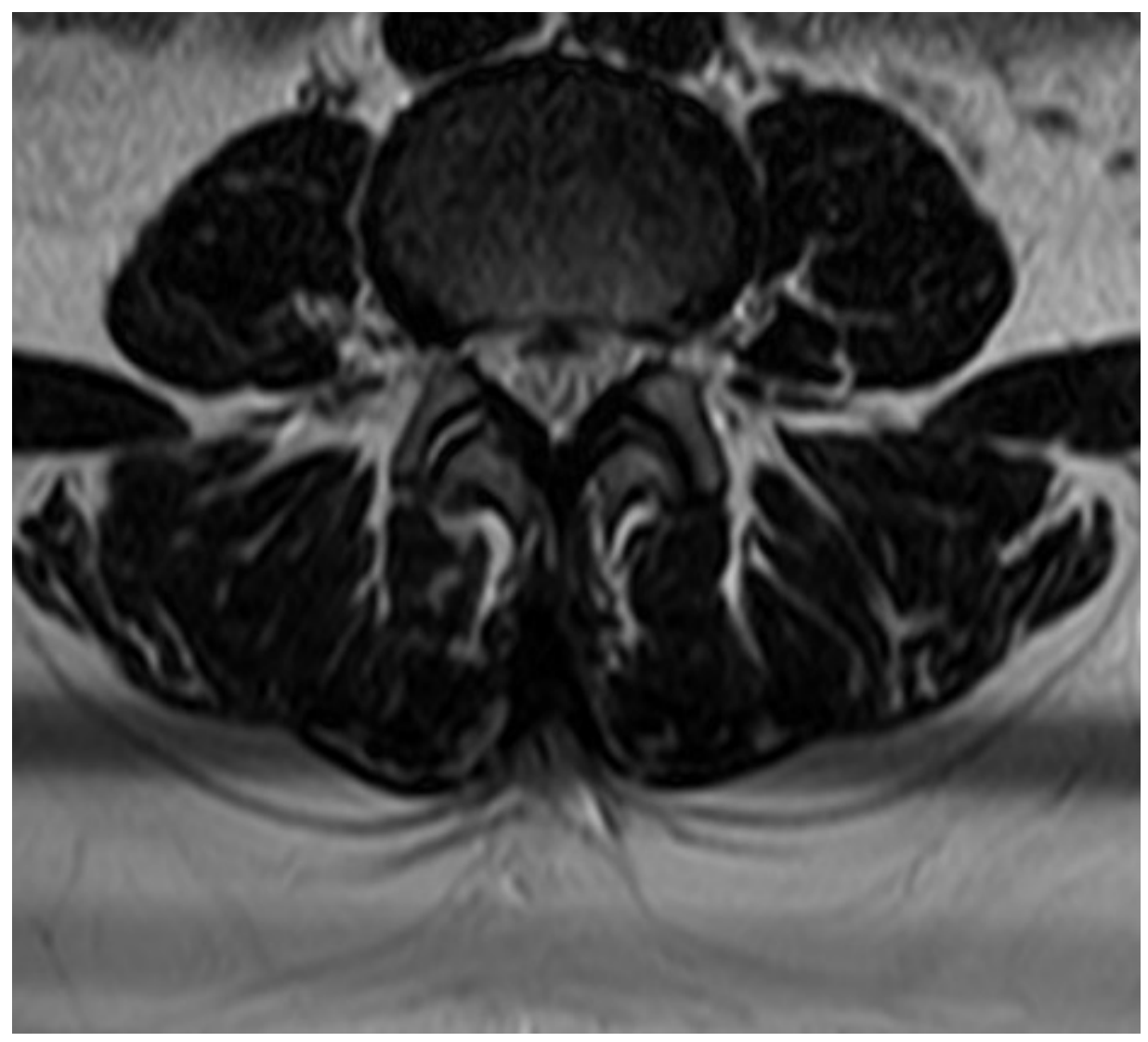

Figure 7

Axial T2-weighted MRI showing shrunken L3-4 disc.

\section{Supplementary Files}

This is a list of supplementary files associated with this preprint. Click to download.

- CAREchecklistEnglish2013.docx 